\title{
The Walia Ibex (Capra walie)
}

\section{Wale Mengistu*}

Ethiopian Biodiversity Institute (EBI), P. O. Box 30726, Addis Ababa, Ethiopia

\begin{abstract}
Walia ibex is endemic mammals of Ethiopia confided to Semien Mountain National Park. It is ungulate of a mediumsized mammal, showing a marked sexual dimorphism and lives between $2600-3900 \mathrm{~m}$ asl mountains of the park. The main threats of this species are human encroachment, habitat loss, livestock grazing and hunting. The population trend is fluctuating. However, currently; it is slightly increasing. Walia ibex is listed as endangered category in IUCN Red List Threatened species. Currently, it is conserved in the park which is administered by both federal and Regional Government. However, for effective conservation of this species, establishing the buffer zone, prohibit hunting, prevent possible Hybridization with goats, Captive-breeding and Awareness creation programs should be proposed and implemented soon.
\end{abstract}

Keywords: Walia ibex; Semien mountain national park; Ethiopia

\section{Introduction}

Ethiopia is one the wild mammal rich countries of Africa which possesses 320 species of wild mammals of which 36 are endemic [1] about a quarter of which are large mammals. These mammals are now restricted to national parks and in protected areas.

Natural habitat is rapidly being converted into landscapes dominated by humans and domestic animals worldwide [2]. Intensive human impact from agriculture, house encroachment, livestock grazing and fuel wood and timber use, poaching and so on, has led to a severe decline of the natural resources of Semien Mountains National Park [3]. Walia ibex, which is one of the members of the unique Semien Mountains' fauna [4], has faced such problem. It is listed as endangered in IUCN Red List Threatened species, hence needs further conservation measures to survive. It is therefore important to review to assess the overall aspect of Walia ibex status and threats to recommend proper conservation management.

\section{Taxonomy of Walia ibex}

Walia ibex (Capra walie) belongs to Order: Cetartiodactyla; Family: Bovidae and Genus: Capra. The genus Capra includes several forms of wild goats (bezoars, turs, markhors, and ibex). In spite of the fact that all Capra species can interbreed in captivity, the systematic of the genus Capra remains unclear [5]. Based on morphological characteristics, some authors considered Walia ibex to be a subspecies of Capra ibex and/or Capra nubiana [6] (Figure 1), while others consider it to be a separate species $[5,7,8]$ which is currently accepted. In addition, molecular studies using mitochondrial and nuclear DNA and ecological niche modeling analysis revealed that the two species are different $[5,8,9]$.

\section{Behavior and reproduction}

Walia ibex is a medium-sized mountain ungulate, with chocolatebrown coat color and showing a marked sexual dimorphism [10] (Figure 2). It is crepuscular mammal living in herd of 5-10; however, females are more solitary than males outside of the breeding seasons [11]. In contrary to other ibex species Walia ibex seems to breed throughout the year [12]. This may be possible because of the lack of temperature seasonality in the tropical Semien Mountains, producing no environmental costs to individuals that breed year-round [13]. But Peak sexual activity between males and females is observed between the months of in March - June overlapping with the short rut season $[11,12]$. Walia ibex individuals reach sexual maturity at the age of one year [14]. Gestation period is about 150 - 165 days and female gives birth one, sometimes two kids per birth [14]. The maximum life expectancy is up to 15 years.

\section{Habitats and feeding}

The Walia ibex lives on steep cliffs in regions characterized by rocky mountain, gorges, outcrops and loose stony screes (Figure 3 ). It depends on undisturbed juniper and other mountain forest, subalpine grasslands and scrub, and a year-round supply of water. Its preference for the escarpment, where the precipitous cliffs offer safety and refuge, may partly be a consequence of past hunting pressure $[4,14,15]$.

Walia Ibex is both a grazer and a browser [14]. In fact, it utilizes a wide variety of grass and shrub material in its diet. Nievergelt (1981) [6] observed Walia ibex feeding on a wide variety of shrubs and herbs, including Giant Heath, Giant Lobelia, the spiny (Figure 4), creepers and lichens and various grasses. Although grazing accounts for a
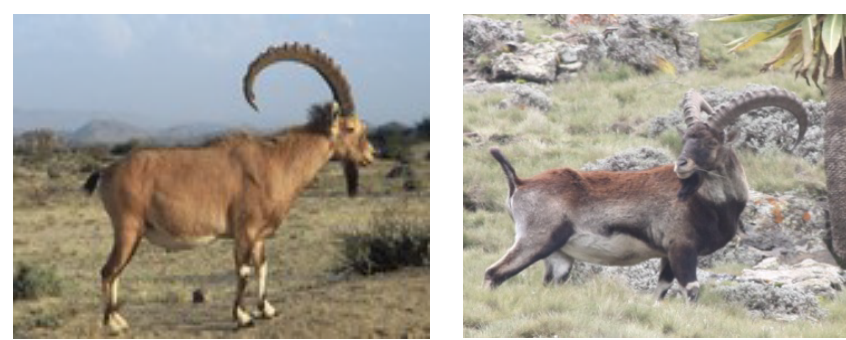

Figure 1: Adult male, Capra nubiana (left) and Capra walie (right), showing not only genetic difference but also slight morphological difference which strengthens the distinction of the two specie. Photo credit: Mengistu Wal (right) and IUCN, 2013 (left).

${ }^{*}$ Corresponding author: Wale Mengistu, Ethiopian Biodiversity Institute (EBI), P. O. Box 30726, Addis Ababa, Ethiopia, Tel: +251116612244; E-mail: mengw2004@yahoo.com

Received April 21, 2016; Accepted June 03, 2016; Published June 10, 2016

Citation: Wale M (2016) The Walia Ibex (Capra walie). J Biodivers Endanger Species 4: 161. doi:10.4172/2332-2543.1000161

Copyright: (c) 2016 Wale M. This is an open-access article distributed under the terms of the Creative Commons Attribution License, which permits unrestricted use, distribution, and reproduction in any medium, provided the original author and source are credited. 

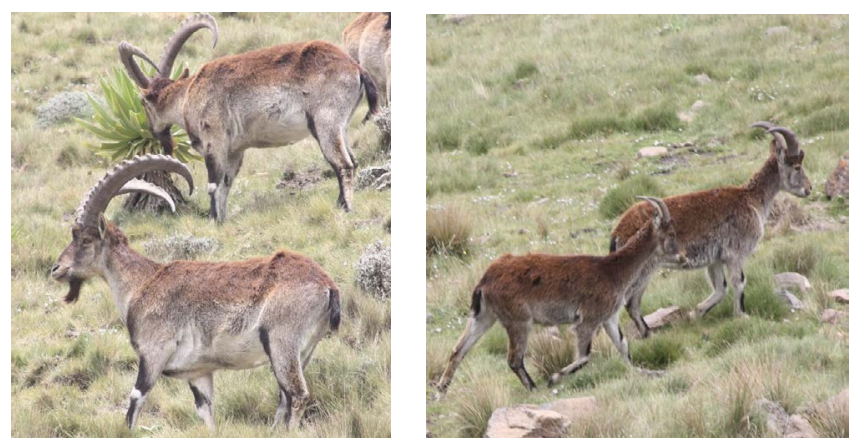

Figure 2: Walia ibex showing sexual dimorphism, male (left) and females (right). Photo credit: Mengistu Wale.
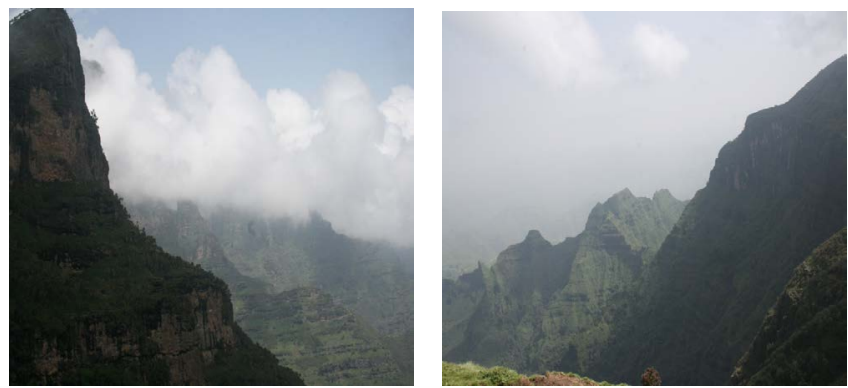

Figure 3: Steeps and cliffs of Semien Mountain National Ppark.

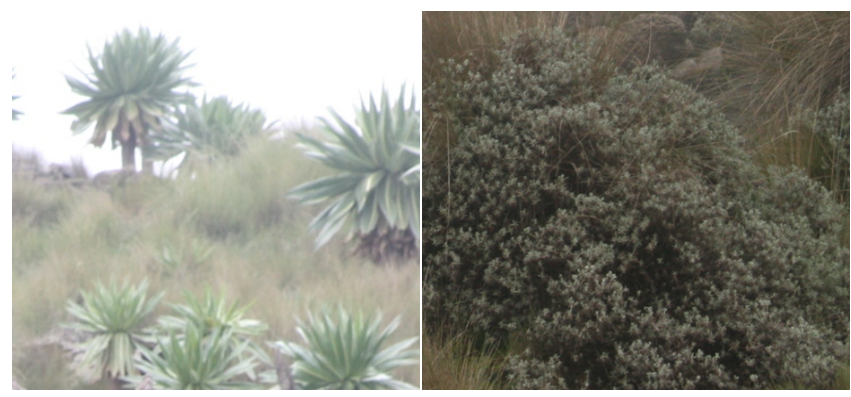

Figure 4: Giant Lobelia (Lobelia rhynchopetalum) left and the spiny (Helichrysum citrispinum) rights are important food source of walia ibex. Photo: Mengistu Wale.

significant part of its diet, this species spends most of its time feeding browsing in the cover of dense shrubs.

\section{Current Distribution of Walia Ibex}

Walia ibex, formerly widespread in the northern mountain massifs, has now a restricted range only in Semien Mountain National Park, northern Ethiopia. The greatest concentration occurs mainly along $25 \mathrm{~km}$ of the northern escarpment between Adarmaz Camp and Chennek Camp. However, there are four small populations outside the park: north of Werkamba, west of the park; between Silki and Walka northeast of the park; between Bwahit and Mesarerya; and just north of Weynobar along the Ras Dejen escarpment to the north $[10,16]$. Walia Ibex were previously found further west in the park and more forage plants are available in the lowlands. However, currently, the distribution of walia ibex is towards Sebatminch in the eastern portion of the park which has more highlands available (Figure 5).

\section{Population trend}

The population of Walia ibex numbered 150 - 300 individuals between 1966 - 1969, increase slowly until 1983 when there were possibly more than 500 individuals, and then decreasing again during the period of civil unrest during the early 1990s [17]. During the civil unrest the area was military strategy as result more Walia ibex were killed by the armed forces and society without any control which cause a drastic declined in population. 1994 and 1996 the population was estimated at 200 - 250 individuals but it subsequently increased reaching about 500 individuals in 2004 [18]. This increase in population was as result of protection effort of the government after the end of the civil unrest. Walia ibex counts have been done at least twice a year in recent times by the Semien Mountain National Park administrations under Ethiopian Wildlife Conservation Authority. The population size has increased slightly, estimated to be 745 individuals during the 2009 count [19]. In 2012, according to Semien Mountain National Park scouts count, the population of walia ibex is estimated between 800 - 850 individuals. Nevertheless, the validity of this number is yet to be confirmed applying rigorous scientific research. The currently increasing the population size of the Walia ibex is mainly due to the gradual increase in conservation management strategies, despite the strategies are not successfully implemented with lack of commitment and other factors.

\section{Threats of Walia ibex}

Walia ibex is one of the most endangered mammal species in the world and is threatened by extinction due to low numbers and the very restricted area of remaining habitat. Furthermore, habitat loss, human settlement, livestock grazing and hunting are few of the major threats to this species (Figure 6) $[3,18]$. Despite the existence of national and regional legislation, the remoteness of the area coupled with the existence of people living within and outside of the Park prior to its establishment as a conservation area makes legislation difficult to enforce [18]. The increase of the human population and with it soil degradation by erosion forced the people to settle and cultivate up to higher and higher as well as steeper and steeper areas of arable land in the course of time. The high numbers of grazing cattle and other domestic animals have an extremely devastating effect on the afro-alpine grassland ecosystem. Today the land use is dangerously high, all accessible areas, even if they offer only

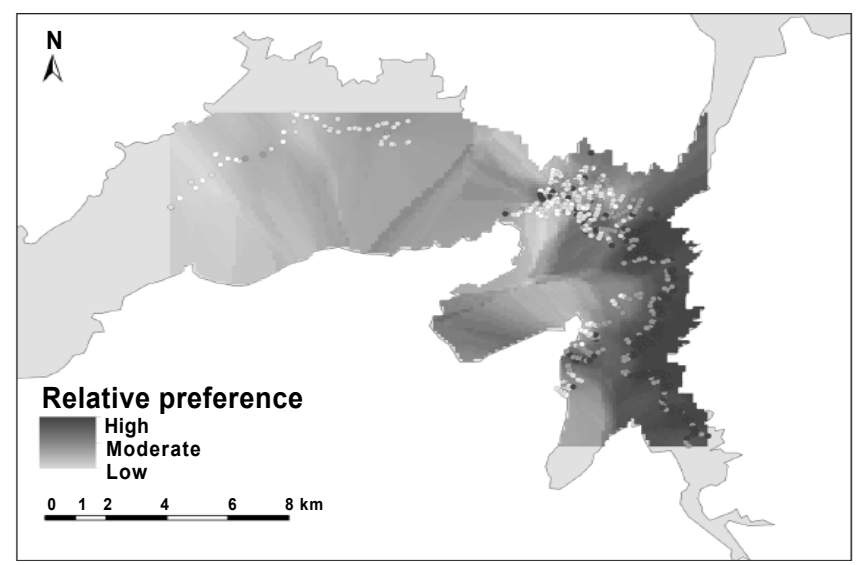

Figure 5: Spatial representation of relative preference of Walia ibex within the Park, defined as the probability of finding a walia ibex pellet at a sample point. Dark areas indicate a higher preference for sample locations and landscape. Source: Ejigu et al., 2015. 
a narrow strip of a few meters between two rocks, are cultivated. A few Walia ibex also move to the south-east of their natural range to feed on cultivated crops at places where there is cultivation of barley and other crops on steep gradients. These incidences occasionally lead to conflict with local farmers.

The environmental impact on wildlife posed by executed road construction (Figure 6) in the park is important as the alignment of the new road between Mindigebsa and Sankaber exactly follows the ecologically vulnerable border zone between the plateau and
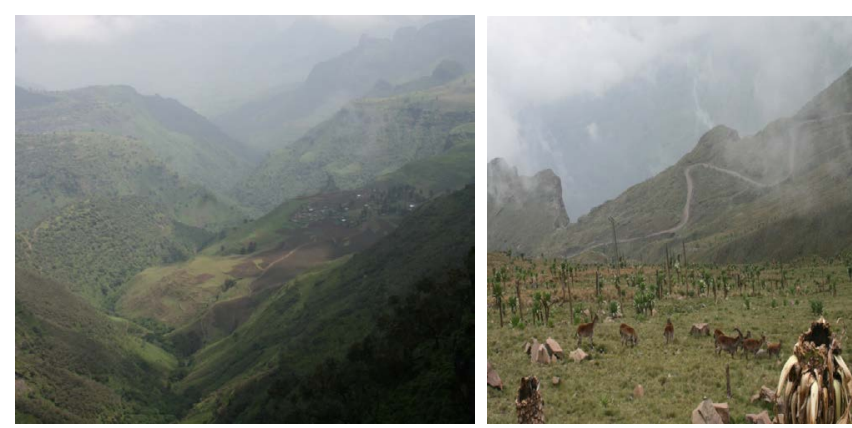

Figure 6: House encroachment (left), road construction (right) in and across the Park. Photo: Mengistu Wale. the heather forest (Figure 7). Here, the road separates a Walia ibex, Klipspringer and Gelada foraging habitat from the sheltering cliffs. The same occurs for the road from Chennek to Bwahit. Additionally, the road cuts straight through the Walia ibex corridor which connects the northern escarpment with the ridges and peaks of Mount Bwahit and Mesarerya.

Walia ibex has been hunted by local people for meat, hides and for horns for drinking vessels for a decade. However, hunting of the Walia ibex in the Park is no longer permitted. Its inaccessible habitat provided protection until the advent of modern firearms, which led to a significant reduction in the population. Although not as large a problem as in the past, hunting still does occur to some degree inside the national park [20].

Disease is important threat that contributes to the decline of wild animals worldwide. In the case of Walia ibex, there is no any scientific evidence that consider disease as major factor to its decline. However, parasitic helminthes infection is common in Walia ibex. According to Basaznew et al., (2013) [21], from a total of 167 fecal samples examined, $85.63 \%$ of Walia ibex were infected by parasitic helminthes. So the conservation measure should also consider these threats.

\section{Conservation}

Over the last half century, Walia ibex has been considered one of

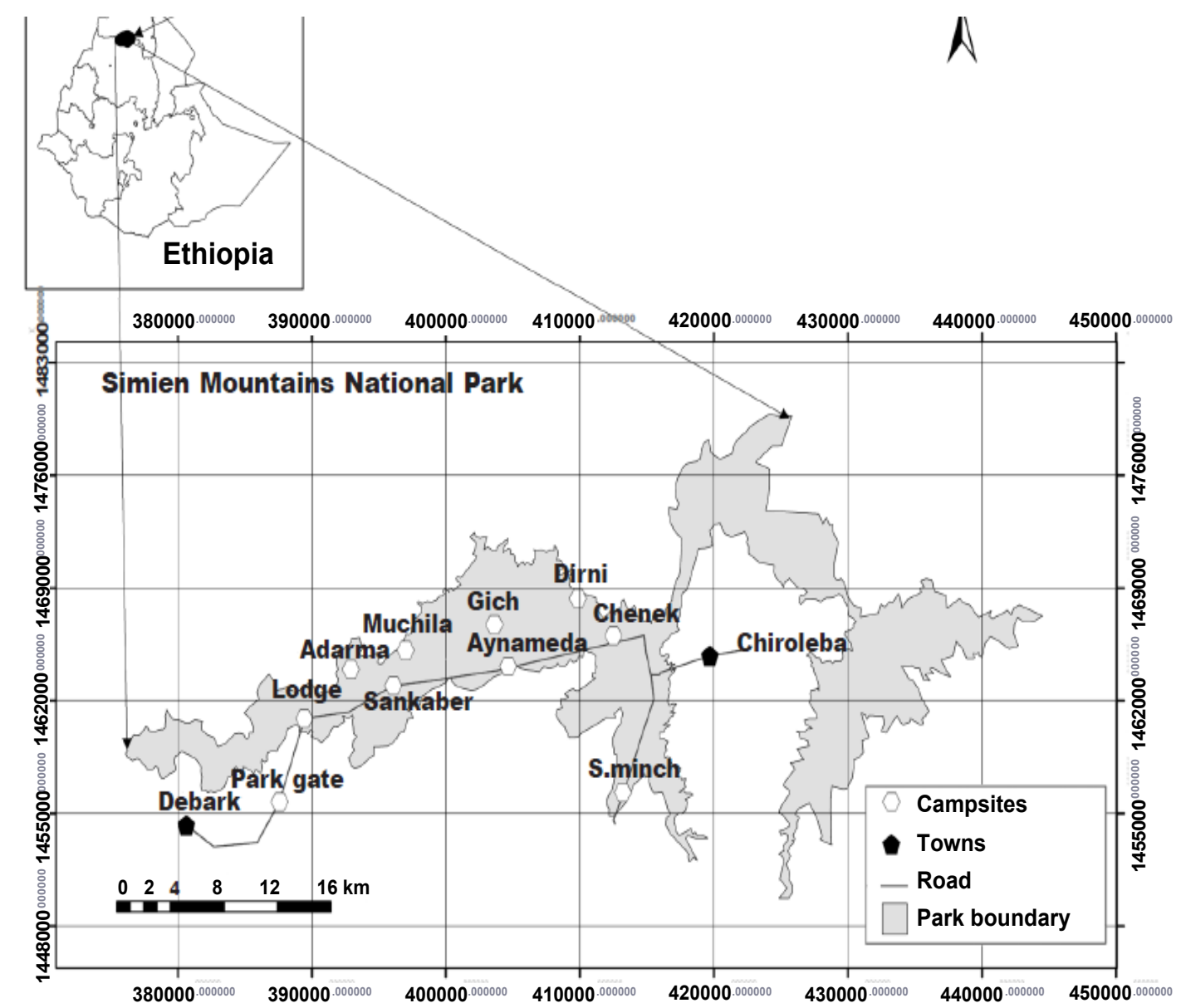

Figure 7: The location of Simien Mountains National Park and Park boundary with associated towns, local camp sites and roads. Source: Ejigu et al., 2015. 
the most endangered ungulates in the world [13]. It was classified as Endangered between 1960 - 1964 and then Critically Endangered in 1996 - 2004; according to the IUCN Red list criteria (Criteria: C2b) (IUCN, 2004) [22] and now this species is treated as Endangered (Criteria; B1ab(iii)); D VER 3.1 [18].

The park attracted international and national attention following its inclusion on the List of World Heritage site and a lot has been done in the conservation of Walia ibex, however with restricted habitat coupled with the currently prevailing threats, further conservation and recovery strategic plan is required. Therefore, the following conservation measures should be proposed and implemented for effective conservation of this species. Some of the ideas recommended below such as preventing hunting, reduce human livestock impacts and awareness creation programs were tried to be in place but not successful. Therefore, author recommends more efforts have to done in all levels to implements these ideas. The establishing buffer zone, captive breeding, introduction and concern of hybridization are not in consideration yet [23].

\section{Buffer zone}

Establishing the buffer zone for Semien Mountains National Park, would increase the effective area of Semien Mountains National park thereby to reduce human and domestic wildlife interaction and increase walia ibex foraging ranges.

\section{Reduce human and livestock impact in the National Park}

House settlement within the Park and cultivation and associated livestock grazing is the main cause of habitat loss. The high numbers of grazing cattle and other domestic animals have an extremely devastating effect on the afro-alpine grassland ecosystem there by reducing availability of food for ibex. Therefore, resettlement of peoples who live inside the park and near the park if possible into an area where the impact would be minimized is the best [24].

\section{Prohibit hunting}

Thought the activity is currently decreasing walia ibex is hunted by local people for meat and hides and for horns for drinking vessels [20]. So prohibiting hunting within and around the Park by enforces regulations effectively and strengthens awareness creation activities with the local peoples.

\section{Hybridization}

Although no hybrids of domestic goats with Walia Ibex have been reported Birhanu Gebremedhin et al. 2009 [8], free-ranging domestic goats must be eliminated from the Park and around other ibex populations to exclude the possibility of hybridization occurrence [25-27].

\section{Introduction}

Since the species only surviving in one area and no specimens in captivity anywhere in the world, this mammal is extremely vulnerable to diseases. Certain livestock diseases may decimate the population in a matter of days. Such risk should be avoided urgently. The most practical and relatively easy measures would be to introduce the animal in a number of separate protected areas with similar ecological conditions such as Guassa Community Conservation Area, Borana Saynt National Park and the newly created Abune Yosef Community Conservation Area [1].

\section{Captive-breeding}

There is no Walia Ibex in captivity anywhere in the world, initiating a captive-breeding group in zoos with strong interest in working with Ethiopia would further contribute to its conservation security.

\section{Awareness creation}

The overall status of species, its distribution range, and economic importance to the local people and country as well and how the local peoples themselves involved in conservation should be properly addressed. And possibly for future reintroduction should be developed both at the general public and local and federal level [28].

\section{Reference}

1. Vreugdenhil D, Vreugdenhil AD, Tilahun T, Shimelis A, Tefera Z (2012) Gap Analysis of the Protected Areas System of Ethiopia, with technical contributions from Nagelkerke, L., Gedeon, K. Spawls, S., Yalden, D., Lakew Berhanu, and Siege, L., World Institute for Conservation and Environment, USA. Wildlife Conservation Society International, New York, and Ethiopian Wildlife.

2. Kidd G, Bowman J, Lesbarrères D, Schulte-Hostedde I (2009) Hybridization between escaped domestic and wild American mink. Mol. Ecol 18: 1175-1186.

3. United Nation Environment Programme - World Conservation Monitoring Centre (UNEP-WCMC, 2008). Semien National Park, Ethiopia.

4. Yalden D, Largen M, Kock D (1984) Catalogue of the mammals of Ethiopia. 5 Artiodactyla. Italian J. Zool. Suppl 19: 67-221.

5. Pidancier N, Jordan S, Luikart G, Taberlet $P$ (2006) Evolutionary history of the genus Capra (Artiodactyla): discordance between mitochondrial DNA and y-chromosome phylogenies. Molecular Phylogenetics and Evolution 40: 739749 .

6. Nievergelt B (1981) Ibexes in an African environment. Ecology and social system of the Walia ibex in the Simen Mountains Ethiopia. Ecological Studies Vol. 40. Springer Verlag, Berlin - Heidelberg - New York.

7. Wilson DE, Reeder DM (2005) Mammal species of the world. A taxonomic and geographic reference. Baltimore: Johns Hopkins University Press.

8. Gebremedhin B, Ficetola F, Naderi S, Rezae R, Maudet C et al. (2009) Combining genetic and ecological data to assess the conservation status of the endangered Ethiopian Walia ibex. Animal Conservation 12: 89-100.

9. Randi E, Mucci N, Pierpaoli M, Douzery A (1998) New phylogenetic perspectives on the Cervidae (Artiodactyla) are provided by the mitochondrial cytochrome $b$ gene. Proceedings of the Royal Society of London 26: 793-801.

10. Shackleton DM (ed.) and the IUCN/SSC Caprinae Specialist Group (1997) Wild Sheep and Goats and their Relatives. Status Survey and Conservation Action Plan for Caprinae. IUCN, Gland, Switzerland and Cambridge, UK. $390+$ vii pp

11. Dunbar R, Dunbar $P$ (1981) The grouping behavior of male Walia ibex with special reference to the rut. Afi.J. Ecol 191251-263.

12. Yalden DW, Largen MJ (1992) The endemic mammals of Ethiopia. Mammal Rev 22: 11 5-150.

13. Nievergelt B (1990) Walia Ibex. Pp. 523-525 In: Grzimek, ed. Grzimek's Encyclopedia of Mammals, Volume 5. McGraw-Hill, New York.

14. Massicot $P$ (2001) Animal info-walia ibex. In: animal information-information on endangerd species.

15. Hurni H (1986) Management plan: Simen Mountains National Park and surrounding rural area. UNESCO World Heritage Committee and Wildlife Conserv. Org., Ethiopia. Berne, Switzerland. p122.

16. Festa-Bianchet $M(2009)$ The Walia ibex is a valuable and distinct conservation unit. Animal Conservation, 12: 101-102.

17. Nievergelt B (2012) Capra walie. Pp. 603-605 In: Kingdon J, Haplpold D, Butynski T, Hoffmann M, Happold,M, and Kalina, ed. Mammal of Africa, volumes 1- 6 .

18. Geberemedhin B, Grubb P (2008) Capra walie. In: IUCN 2013. IUCN Red List of Threatened Species.

19. Alemayeh K, Dessie A, Gizaw S, Haile A, Mekasha O (2011) Population 
dynamics of Walia ibex (Capra walie) at Simien Mountains National Park, Ethiopia, African Journal of Ecology 3: 292-300.

20. Beyene B (2001) Walia ibex. Accessed on December 13, 2013.

21. Bogale B, Melaku A, Chanie M, Fentahun T, Berhanu A (2013) First Report of Helminth Parasites of Walia Ibex (Capra walie) at Simen Mountains National Park, Natural World Heritage Site, Northern Ethiopia. Faculty of Veterinary Medicine, University of Gondar, P.O. Box 196, Gondar, Ethiopia.

22. IUCN (2004) Animal Info - Walia Ibex. In: Animal info endangered animals.

23. Dunbar RIM (1978) Competition and niche separation in a high altitude herbivore community in Ethiopia. East Afr. Wildllife 16: 183-199.

24. Ejigu D, Bekele A, Powell L, Lernould JM (2015) Habitat preference of the endangered Ethiopian walia ibex (Capra walie) in the Simien Mountains National Park, Ethiopia. Animal Biodiversity and Conservation 38.1: 1-10.

25. Kingdon J (1997) The Kingdon field guide to African mammals. London Academic Press.

26. McDonald D (1984) Goat antelopes. Pp. 584-589 In: McDonald, ed. Encyclopedia of mammals. New York: facts on file publication.

27. Randi E (2008) Detecting hybridization between wild species and their domesticated relatives. Mol. Ecol 17: 285-293.

28. Gebremedhin B, Ficetola F, Flagstad O, Taberlet P (2010) Demography, distribution and management of walia ibex (Capra walie). Galemys 22 ( $n^{\circ}$ especial): 421-432. 